quimeras 


\title{
Retratos de múltiplas Índias
}

\author{
WILLIAN LUIZ DA CONCEIÇÃO \\ Universidade Federal do Rio de Janeiro - Museu Nacional, Rio de Janeiro, Brasil
}

\section{DOI 10.11606/issn.2316-9133.v28i1p146-153}

Eu chegava à Índia em quatorze de fevereiro de 2014 para uma curta estada. Faria parte do apoio de pesquisa de uma colega brasileira que desenvolvia seu trabalho sobre história do país, mais particularmente sobre a colonização portuguesa em Goa e as ações da Inquisição na região. Como o tempo era curto, dividimos a viagem em dois momentos, trabalharíamos três semanas intensamente nos arquivos em Panaji e como era a minha primeira vez na Índia, iriamos por igual tempo fazer uma viagem por alguns outros estados e cidades. Saí de São Paulo, o voo possuía escalas em Lume, na República Togolesa e depois Addis Ababa, na Etiópia. Às 4:40h da manhã eu estava em Mumbai, estado do Maharashtra, após uma confusão no aeroporto com documentos de entrada no país. Nossas reservas foram confirmadas em um hostel perto do Taj Hotel e do Gateway of India onde ficaríamos por três dias. No caminho do aeroporto para o hostel, o primeiro impacto foi estar no trânsito de Mumbai. São milhares de autorickshaws ou tuk-tuk - como são mais conhecidos -, esses veículos de três rodas em que o preto e amarelo são predominantes, mas se encontram também em verde e amarelo. Nosso condutor descolava-nos em buzinas como em um diálogo frenético entre outros tuk-tuk e motocicletas, cruzavam perigosamente um na frente do outro, como em uma dança melindrosa. A buzina servia ao mesmo tempo como freio e boas-vindas.

Ao descer do hostel e dobrarmos uma rua víamos o mar e centenas de embarcações, muitas delas com vários andares e tomadas de cores, o que conferia ao mar uma beleza inimaginável. Logo em seguida, caminhávamos pela frente do Taj Hotel e minha amiga me contava do atentado terrorista que havia ocorrido em novembro de 2008. No caminho até o Gateway of Índia, víamos umas centenas de pessoas, famílias, as quais eram em sua maioria casais, que tiravam fotografias juntos ao portal. Algumas enamoradas tinham rosas vermelhas nas mãos. A tarde passeávamos no centro e me impressionava os altos prédios no estilo britânico, a quantidade de gente na rua, as mulheres jovens e idosas vestidas com sáris coloridos, o cheiro dos doces de rua, preparados em grandes tachos, principalmente por homens, os deliciosos Gulab Jamun, o Jalebi, ou ainda, os pani puri (ou puchkas). Este último, uma casquinha arredondada e oca que completada por uma espécie de sopa fria, explodia na boca causando as mais variadas sensações ao mesmo tempo. Ainda no centro caminhávamos e percebíamos a quantidade de bancas de jornais e os taxistas parados em uma grande avenida após o almoço - dentro deles alguns motoristas dormiam um sono 
tranquilo. $\mathrm{O}$ carro era seu lugar de trabalho, seu ganha-pão, mas também a sua casa. $\mathrm{O}$ branco e preto da fotografia, combinados, fazem surgir reflexos, texturas, tons e marcas que envolvem variadas percepções da vida.

Após, nos deslocamos até o Shivaji Park onde um grande número de homens vestidos de calça, camisa e boné branco praticavam críquete. As moças os observavam entusiasmadas. Lá um rapaz me olhou com interesse, como se soubesse que eu não era dali, ele estava com seus amigos assistindo o jogo, saquei a câmera e ele sorriu, tragou seu cigarro como se quisesse que eu o fotografasse neste ato ao brincar com a fumaça que subia. Infelizmente o nervosismo e a necessidade de regulagem da câmera me fizeram perder a cena. Entretanto, depois disso, o jovem rapaz se abaixou me olhando milimetricamente entre as grades de um portão, como se tivesse com outra câmera que me destrinchava - não é possível ao etnógrafo que porta uma câmera estar oculto e imperceptível às pessoas que reagem, protestam, miram-no e que também o fotografam em sua memória. Perto do Shivaji Park, paramos para uma xícara de chai indiano (chá) e víamos um rapaz que fazia alguns chapatis, um tipo de pão sem fermento, de espessura bem fina. Uma janela nos separava, de onde subia um mormaço e um vapor de gordura, mas podíamos observar a habilidade em fazer a massa e fritá-la em um grande tacho. No salão que estávamos o cheiro do pão se mesclava aos dos chás, dos leites com especiarias (identificava no ar o cardamomo e o gengibre), e dos doces expostos em uma grande vitrine. Após alguns dias, embarcamos para Varanasi - uma das cidades mais antigas do mundo e considerada pelos indianos hindus a cidade mais sagrada da Índia.

Em Varanasi nos hospedamos próximos do rio Ganges, o primeiro estranhamento foi perceber que a cidade era coberta por uma nevoa baixa, em grande medida decorrente da atividade de cremação humana que ocorre nos gates aos pés do Ganges, durante todo o dia, concentrando milhares de peregrinos vindos de todo país. No primeiro dia contratamos um barqueiro que nos apresentou o rio e contou os seus segredos, do passeio avistávamos os peregrinos que se banhavam, lavavam roupas, estendendo-as nas antigas escadarias ou mesmo nas embarcações. Ao descermos observamos um sadhu que lia um jornal, com suas pernas cruzadas, suas roupas sagradas, ao sacar a foto quis apresentar em profundidade um pouco dessa cidade espetacular e fantasmagórica.

Com uma população de cerca de 1,324 bilhão de pessoas, a Índia é um país de dimensões continentais e múltiplas culturas. As diferenças geográficas e ecológicas, os conflitos étnicos e religiosos históricos, as situações das castas, as múltiplas línguas faladas no território, tornam as distintas Índias um ambiente propício aos estudos etnográficos contemporâneos. Por outro lado, nos força a um retorno necessário às obras clássicas da antropologia que buscaram descrever a diversidade e a heterogeneidade do país. $\mathrm{O}$ ensaio $=$ buscou diferentes aspectos de cidades, vilas, paisagens humanas e ambientais, sensível às cores das roupas, dos veículos, motorizados ou não, os cheiros das comidas, das especiarias e dos perfumes usados, o momento de lazer, do descanso e do trabalho, as práticas litúrgicas e as expressões políticas, que apresentam Índias complexas e encantadoras. As 
cidades aqui fotografadas em março de 2014 e apresentadas de forma inédita nesse ensaio são Mumbai e Varanasi.
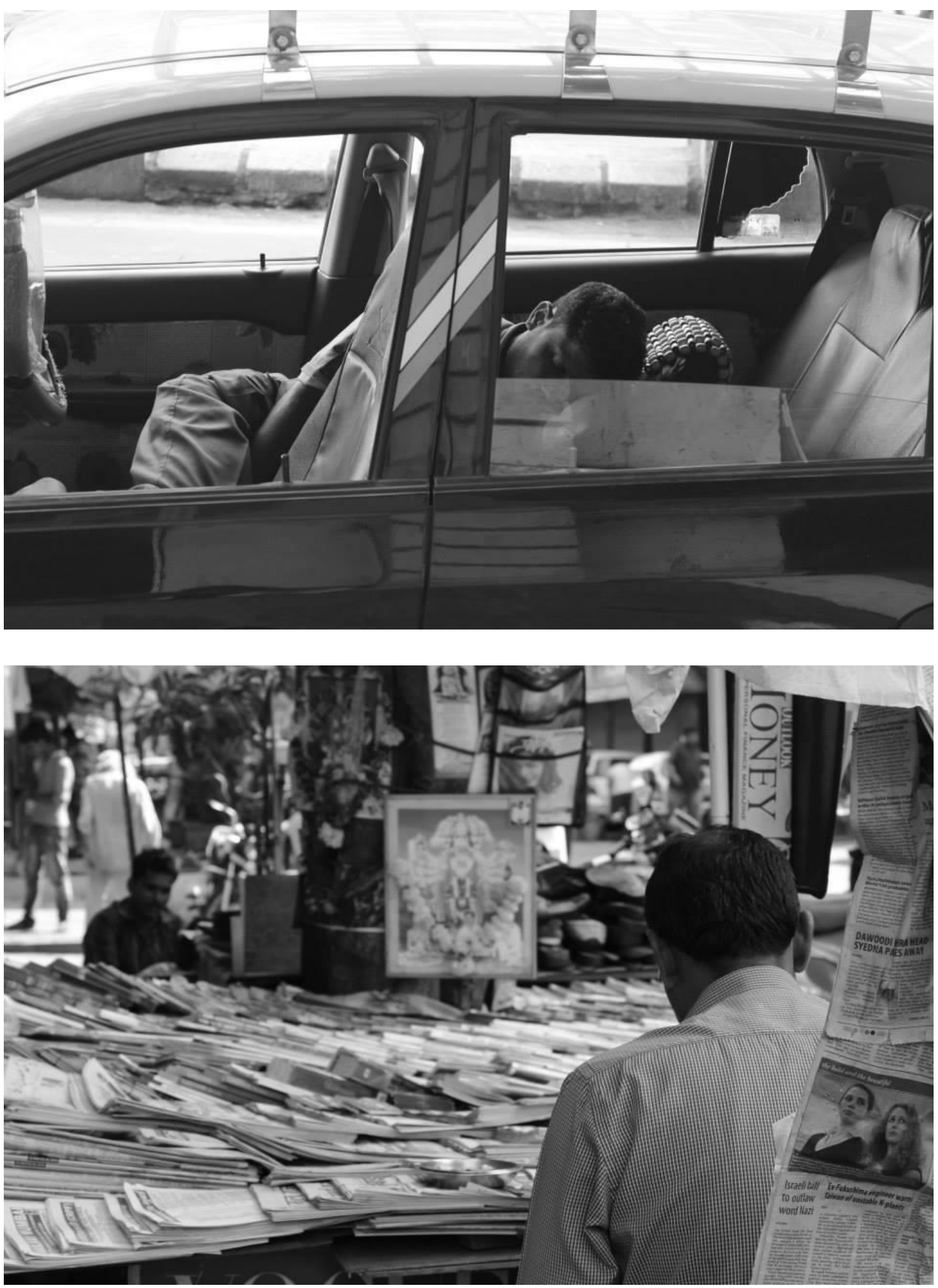

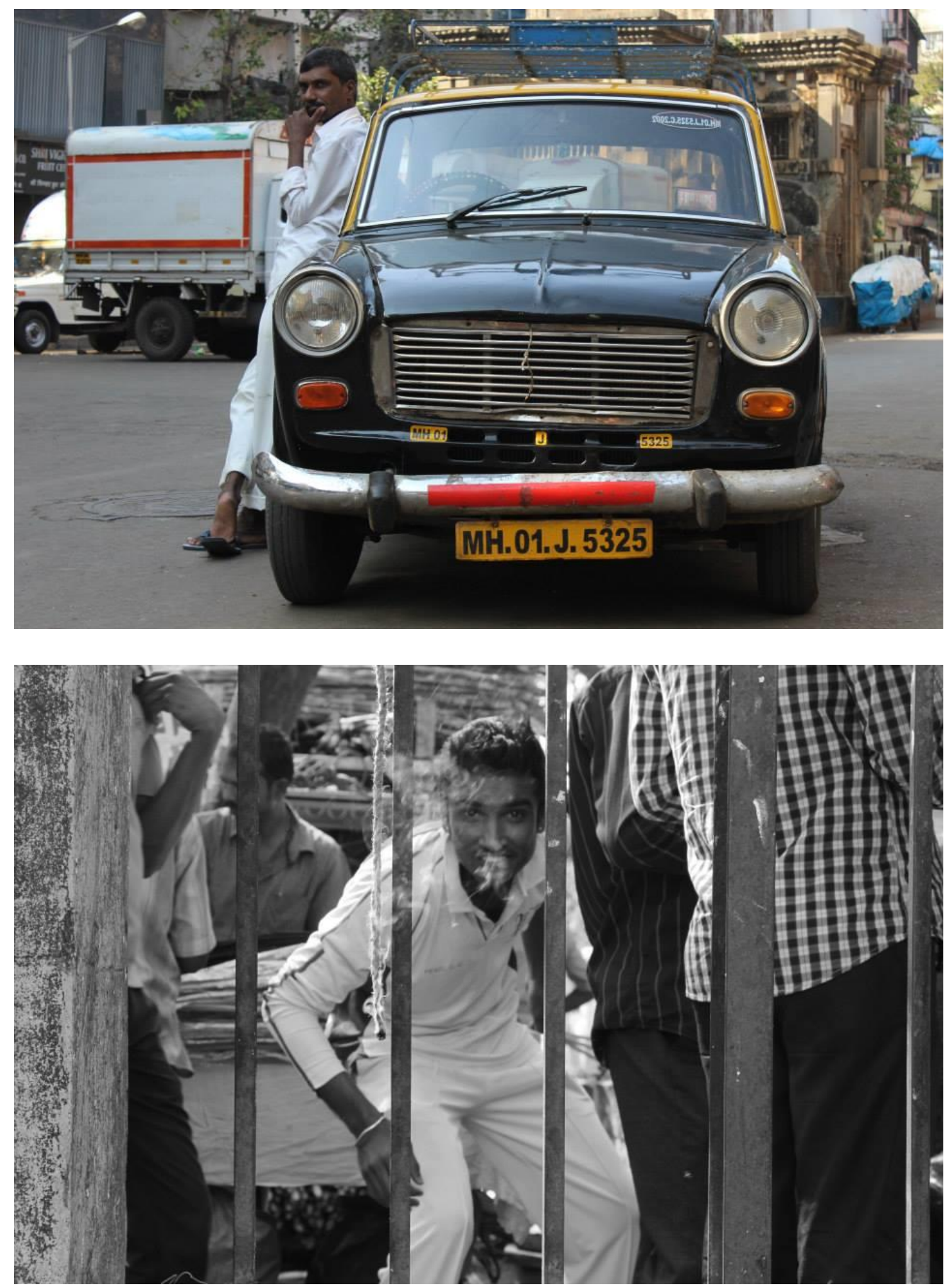

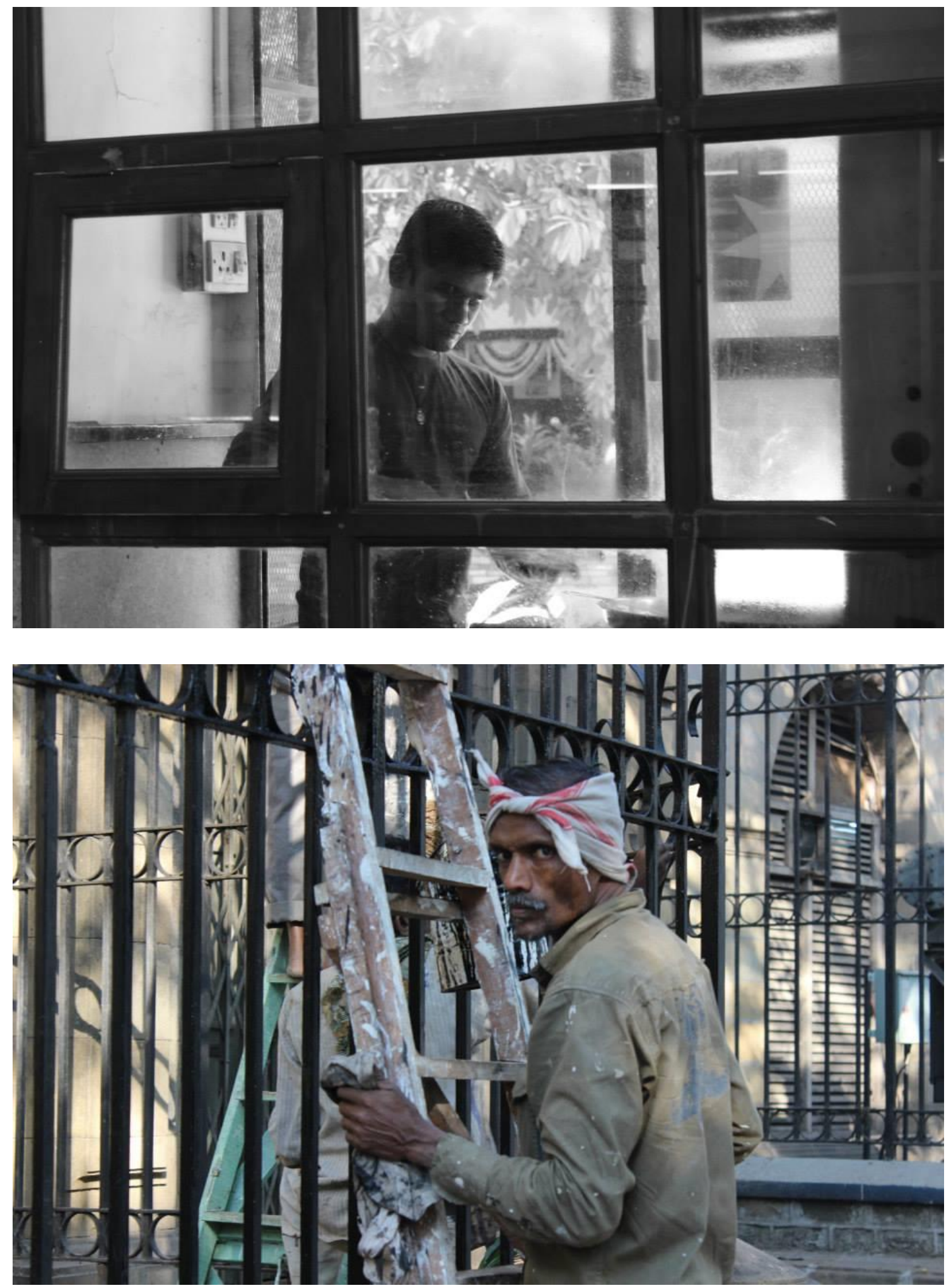

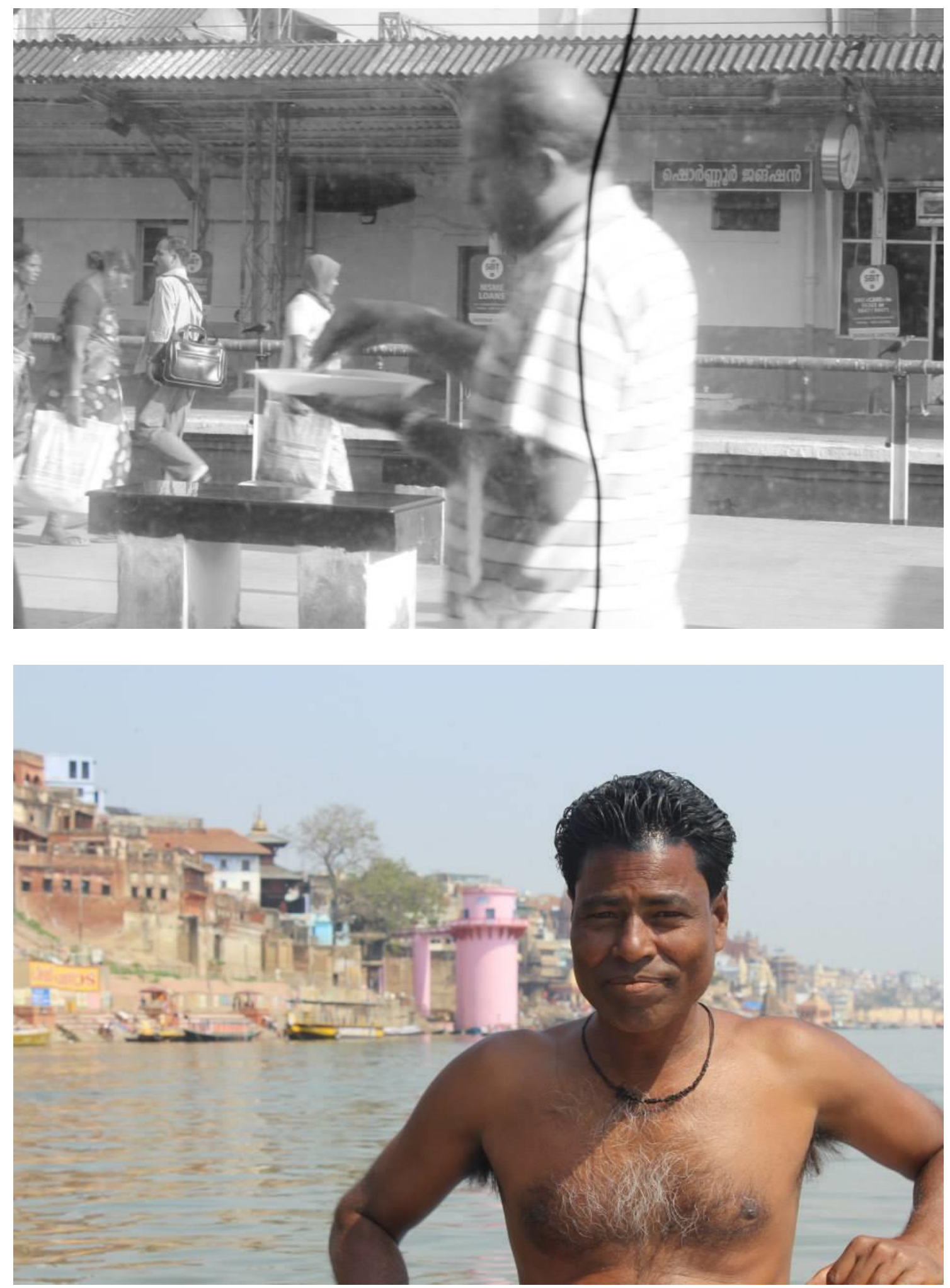

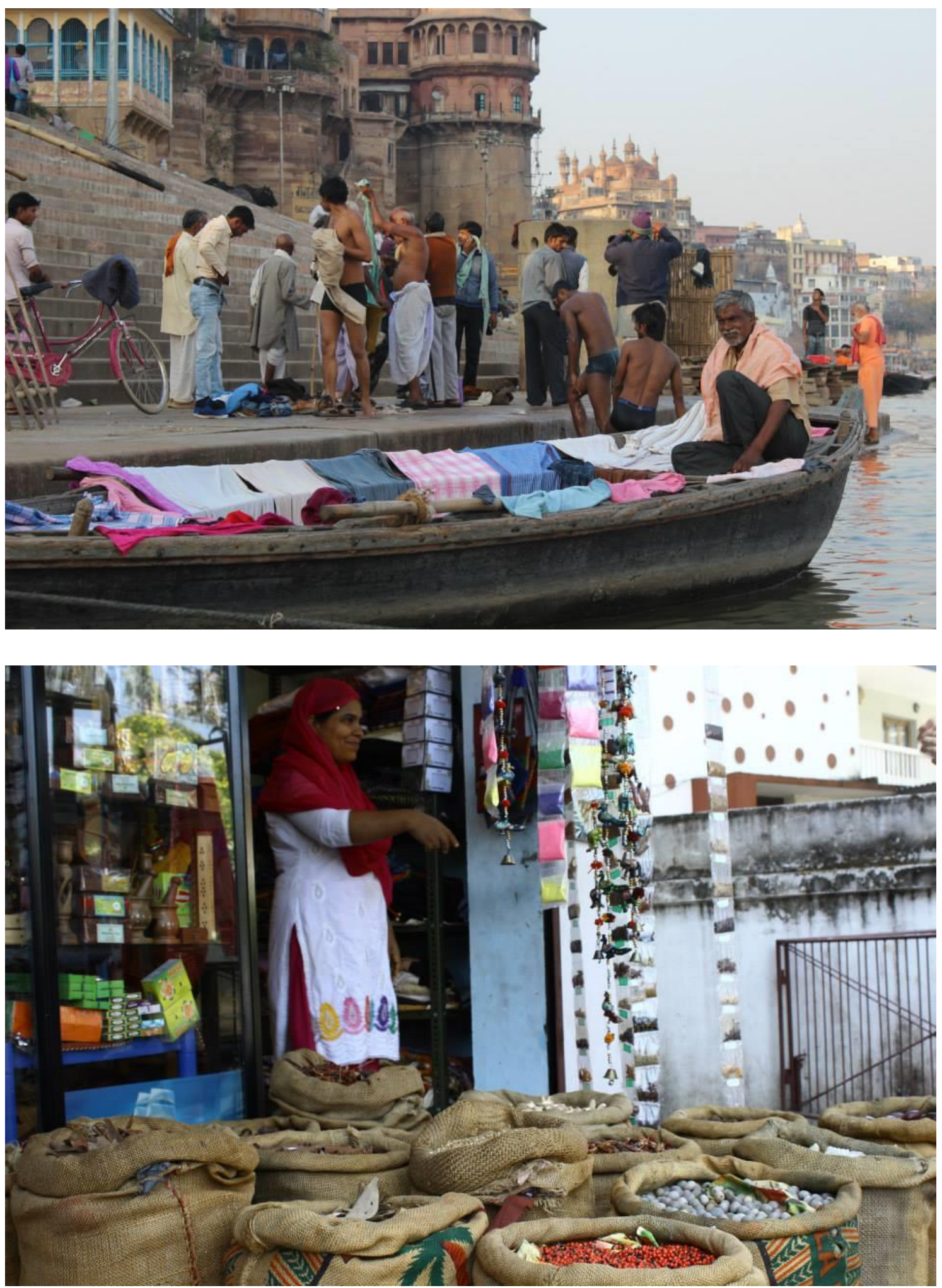


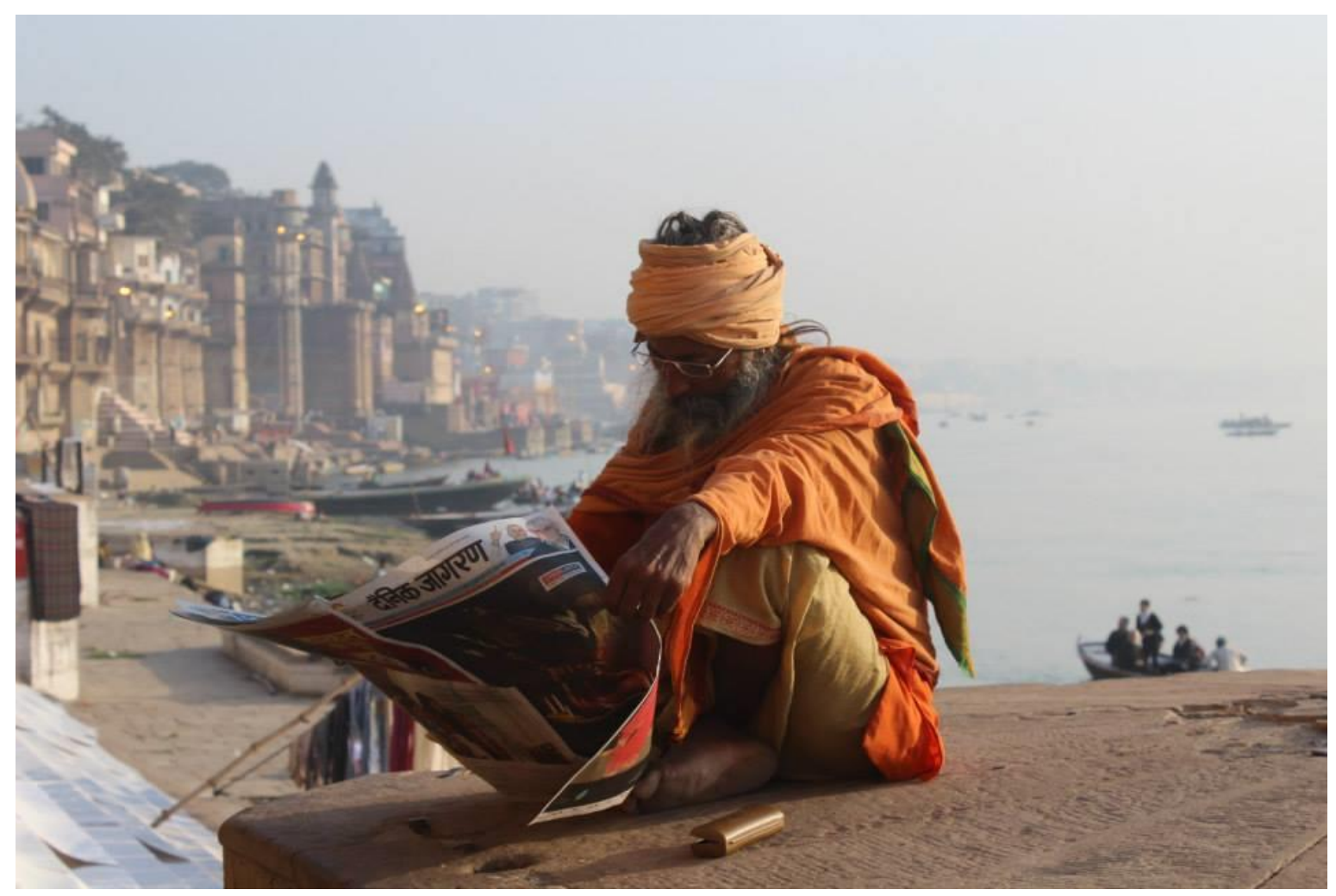

autor Willian Luiz da Conceição

É doutorando em Antropologia Social pelo Museu Nacional da UFRJ, com mestrado em Antropologia Social pela Universidade Federal de Santa Catarina.

Recebido em 02/02/2018

Aceito para publicação em 30/11/2019 